\title{
Knowledge-Based System for Tobacco Weed Management
}

\author{
H. Ravisankar ${ }^{1 *}$, S. Kasturi Krishna ${ }^{2}$, D. Damodar Reddy ${ }^{3}$, \\ V.S. G. R. Naidu ${ }^{4}$ and B. Hema ${ }^{5}$ \\ Central Tobacco Research Institute, Rajahmundry, Andhra Pradesh - 533 105, India \\ *Corresponding author
}

Keywords

Tobacco, Weed,

Knowledge,

System,

Management

Article Info

Accepted:

18 May 2020

Available Online:

10 June 2020

\section{A B S T R A C T}

Tobacco is an important commercial crop which has no exception for weed menace and associated losses. Weeds affect the crop directly by reducing leaf yields through competition for basic resources and indirectly as foreign matter lowering the cured product quality. The primary step in developing an efficient weed management system is identification of the weed which requires practical expertise. As an expert is not always accessible for identification, a knowledge-based system for tobacco weed management was developed based on data available on various parameters of weeds using Personnel Home Page (PhP) and HTML languages. This user friendly program consists of 24 modules while the database has various parameters of the weed viz., scientific name, family, description, control and photograph. This software facilitates easy access to the user by searching with a photo / scientific name/ family in both weed identifying and its management practices in a single go from any location.

\section{Introduction}

Weeds are common in natural and managed ecosystems and have significance when they cause crop yield losses or damage the biodiversity with their invasive nature. Estimates show that one third of the crop yield losses are due to weeds necessitating focusing of attention similar to that on insect pests and diseases. Weed management can be planned only after understanding the biology and ecology of the targeted weed. The identification is the primary step in studying the weed biology and its life cycle. Weed identification with no difficulty is possible to those who have expertise in this field with long-term work experience but cannot be possible for a layman or a non-expert.

Unfortunately, specialized assistance is not always available everywhere for weed identification. In order to overcome this problem, Knowledge Based System (KBS) for tobacco weed management was developed to provide instant access to information on weeds and their characteristics. 
KBS is useful for scientists, researchers, extension workers and farmers to a large extent in decision making on weed management. In this paper, an emphasis has been made for the control of various weeds infesting tobacco crop using an information system based on weed identification and its management.

\section{Knowledge based systems in agriculture}

The Knowledge based systems (KBS) are computer programs that require human expertise and knowledge base in that domain (Donald 2009, Patterson 2004). One of the applications of knowledge-based systems in agriculture is development of databases for weed identification and management. In agriculture, knowledge based systems were developed in various disciplines viz., plant breeding, pathology, entomology, agronomy and extension (Ahmed Rafea 2010, Chakrabarti and Chakraborty 2007, Gonazalez et al., 1990, Prasad et al., 2006, Sarma et al., 2010, Babu et al., 2010, AniDath and Balakrishnan 2016). These systems were developed as a combined effort of subject matter specialist /expert and a computer programmer. At ICAR-CTRI, we have developed various knowledge based systems viz., identification of tobacco insect pests and diseases, tobacco germplasm, soil and water analysis, diagnosis of nutrient deficiencies in FCV tobacco, etc. (Ravisankar et al., 2014, 2012, 2009a, 2009b, 2010).

\section{Knowledge based systems on weed management}

Knowledge based system on identification of weeds was developed by various researchers (Schulthess et al., 1996, Lonchamp et al., 1991). Directorate of Weed Science Research, Jabalpur, India has developed an expert system for identification of 337 weed species (Naidu et al., 2014). This system identifies a particular weed by selecting the Family name, habit, shape of stem, leaf, fruit \& seed and flower colour. Western Australian Department of Agriculture has developed an expert system for the identification and control of weeds in wheat, triticale, barley and oat crops named as "Weed Adviser" which is a rule-based system that helps in identifying a weed, offers control measures, indicates herbicides that should not be used and provides additional herbicide information (Pasqual 2013). Similar expert systems for identification of weeds in maize (Montalvoa et al., 2013), potato (Sabzia et al., 2018) and olive crops (Andujar and Luis 2009) were also developed.

\section{Knowledge based system for tobacco weed management}

The Knowledge Based System (KBS) for tobacco weed management was developed with a view to help the user in identifying correct weed by specifying its characteristics from a variety of categories, viz., Scientific Name, Weed Name, Description, Family and Photo. The developed system also supports to print the generated report for the selected weed. When compared with the other systems developed for weed management, the present system on tobacco weed management provides easy access to the required information for a particular weed from the home page of the software and reduces the number of selections to be made by the user for identification.

In tobacco, weed management is done by intercultural operations till now and recently scientists have developed integrated weed management practices including herbicides. Therefore, the identification of weed and integrated management of the weeds included in the knowledge base system for weed management in tobacco is first of its kind and no one has attempted to develop such a 
system till date. KBS will help in the transfer of technology to all the stakeholders of tobacco in India.

\section{Materials and Methods}

The Knowledge-Based System for tobacco weed management has been developed as a combined effort with the help of experts in the field of weed science, agronomy (subject matter experts) and software specialist. KBS design (Kiong 2005) composed of several basic components: a user interface, database, knowledge base and an inference mechanism (Fig. 1). The initial step for developing the knowledge base system is knowledge acquisition (Spangler et al., 2003).

Based on the information collected on tobacco weeds from the experts, a datasheet has been prepared with various parameters viz., scientific name, family name, weed description, weed name along with weed images. For capturing the weed images, field surveys were conducted in the farm during tobacco crop growth period. Every effort was made to get the images of the weeds at its appropriate stage of growth that represented its correct identity / easy identification. Using this datasheet, a database was designed in MySQL (Vikram 2017). In the knowledge base, information on tobacco weeds can be stored as rules of inference that are used during the reasoning process for knowledge extraction of tobacco weeds.

The inference mechanism guides the reasoning process through knowledge base by attempting to match the facts in the database to other rule conditions. Inferences are identified to meet the user requests to find availability of the data in tobacco weeds knowledge base. After successful analysis of the knowledge base by the weed scientist, the system for tobacco weed management has been developed using $\mathrm{PhP}$ and HTML languages consisting of 24 modules.

\section{Database structure}

Database of this system contains information about 10 tobacco weeds viz., Cynodon dactylon (Pers); Cleome viscose (Linn); Cyperus rotundus (Linn); Portulaca oleracea (Linn); Digitarias anguinalis (Linn); Phyllanthus niruri (Linn); Dactyloctenium aegyptium (Beauv); Trianthema portulacastrum (Linn); Panicumrepens (Linn) and Euphorbia hirta (Linn).

These 10 tobacco weeds belong to six families viz., Gramineae, Capparidacea, Euphorbiaceae, Portulacaceae, Cyperaceae and Aizoaceae. For each weed, five characters were stored in the database viz., scientific name, family name, weed description, control and weed photo. Information about some of the important weeds is given below.

\section{Cynodon dactylon(Pers)}

This weed belongs to 'Gramineae' family and it is a very hardy, much branched, leafy grass with numerous stems below and above soil. They grow to a length of 1-2 feet, or more and form thick patches. The method suggested to control this weed is digging out the patches of the grass by means of crow-bars /post emergence application of quizalofop ethyl @ $60 \mathrm{~g}$ ai/ha during crop growth stage / intercultural operations / hand weeding with sickles to remove the stems completely from the affected area.

\section{Digitaria sanguinalis(Linn)}

This weed belongs to 'Gramineae' family and its characteristic features are stout culms, usually decumbent at the base, smooth and $30-90 \mathrm{~cm}$ long when prostrate. The leaves are $5-15 \mathrm{~cm}$ long, $5-10 \mathrm{~cm}$ wide and somewhat hairy. Post emergence application of Quizalofop ethyl@60g ai/ha during crop 
growth/ intercultural operations / hand weeding are the control measures followed.

\section{Euphorbia hirta(Linn)}

This weed belongs to 'Euphorbiaceae' family and it occurs in the plains. E. hirta, is the most widely distributed and commonly found weed. It is hardy, rather deep-rooted annual with plenty of milk juice in all it parts.

Branches are few, sub-erect, erect, or ascending and attain a height of a foot or more. Leaves are simple, opposite, shortly stalked with very small linear stipules. Intercultural operations / hand weeding are the general control methodsused.

\section{Cyperus rotundus (Linn)}

This weed belongs to 'Cyperaceae' family and it is an erect, glabrous herb growing to a height of 3-9 inches with perennial underground stems spreading over an area of even 20square feet or more. It is one of the most noxious weeds of cultivation, its spread is so great, and its ravages are so serious in certain places. Control measures include post emergence application of Glyphosate before planting tobacco / intercultural operations / tracing and digging out the tubers.

\section{Results and Discussion}

This software is a user-friendly system and provides a set of facilities to easily store, retrieve and update the information on tobacco weeds. The homepage of this system (Fig.2) consists of four options namely 'Introduction, Selection by Photo, Selection by Scientific Name and Selection by Family'.

'Introduction' provides basic information about the weeds and their management. If the user chooses the 'Selection by Photo' option from the homepage, a new screen with images of all the weeds stored in the knowledge base gets displayed (Fig. 3). By selecting one of the photos as per the requirement of the user, a new screen with 'Scientific Name, Family, Weed description, Control and image' of that particular weed gets displayed.

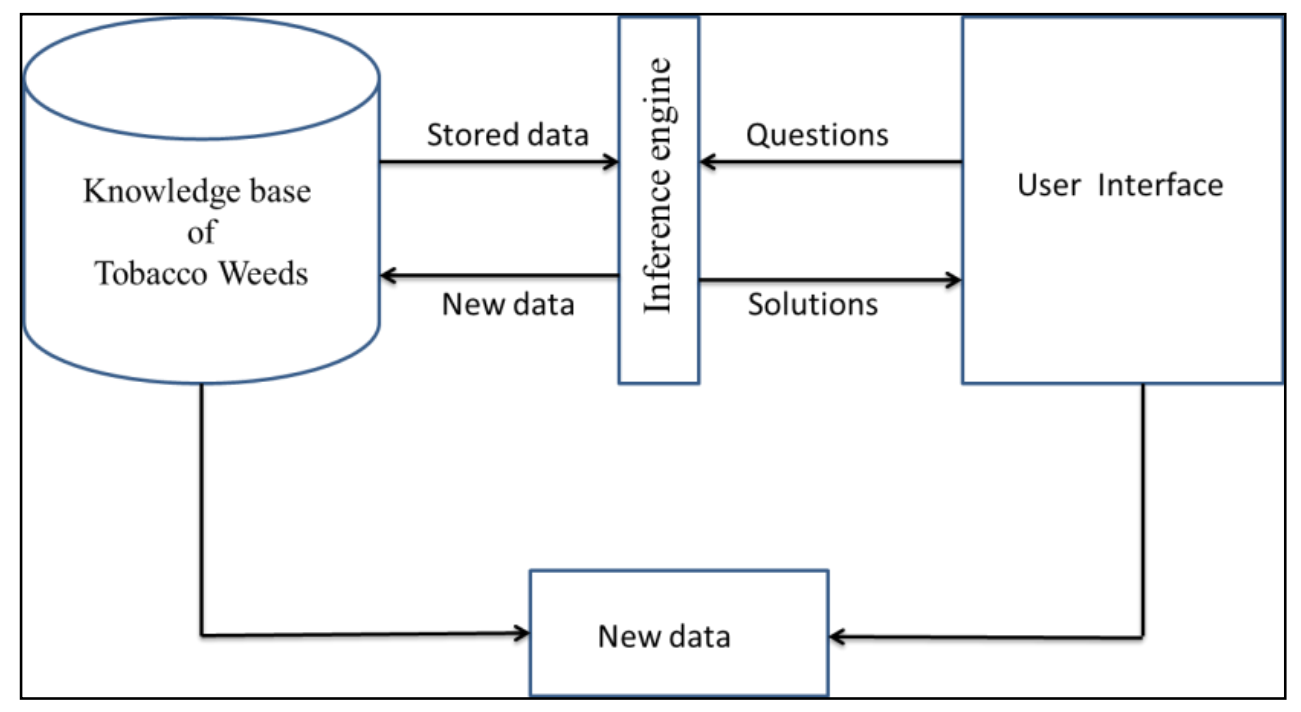

Figure.1 Knowledge base system Architecture 


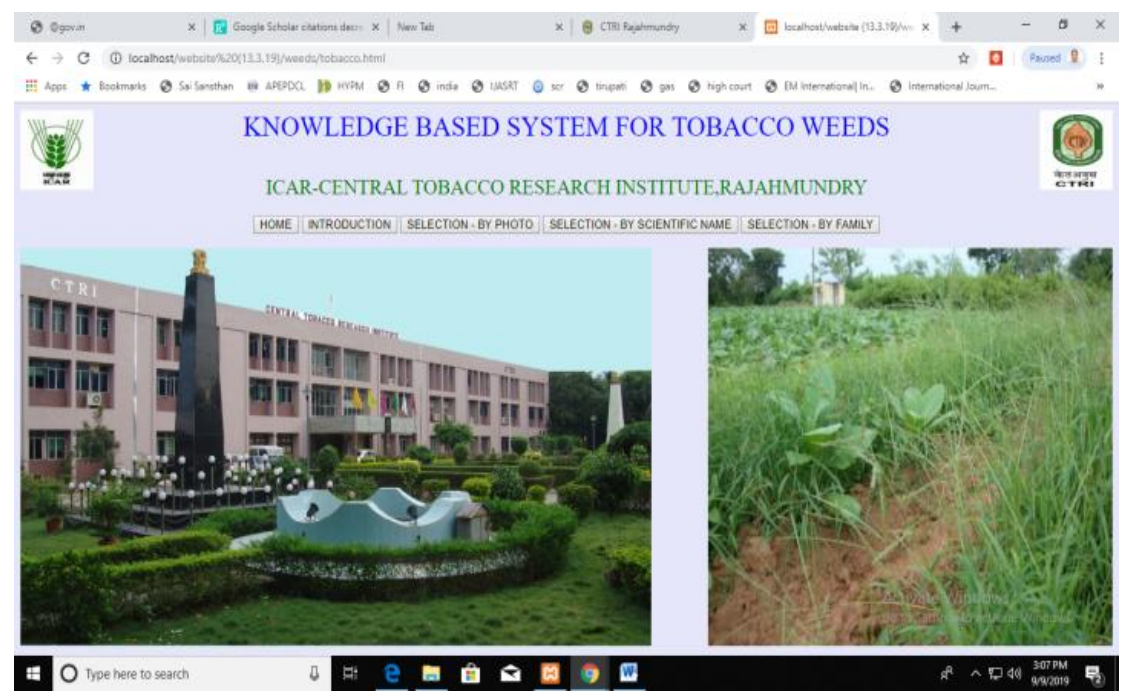

Figure.2 Main Menu

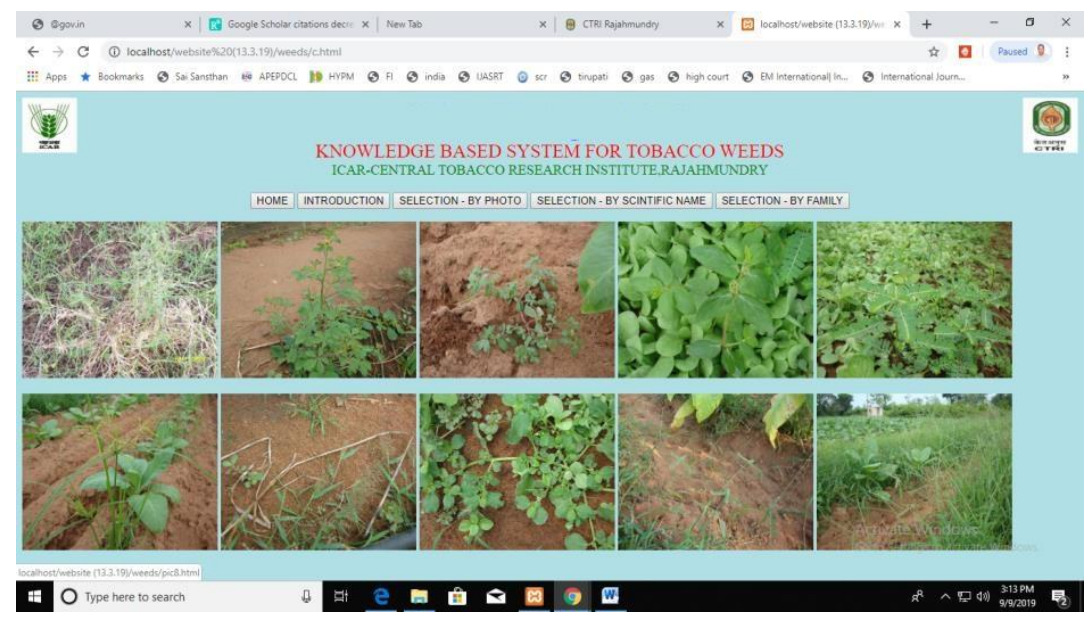

Figure.3 Selection by Weed Photo

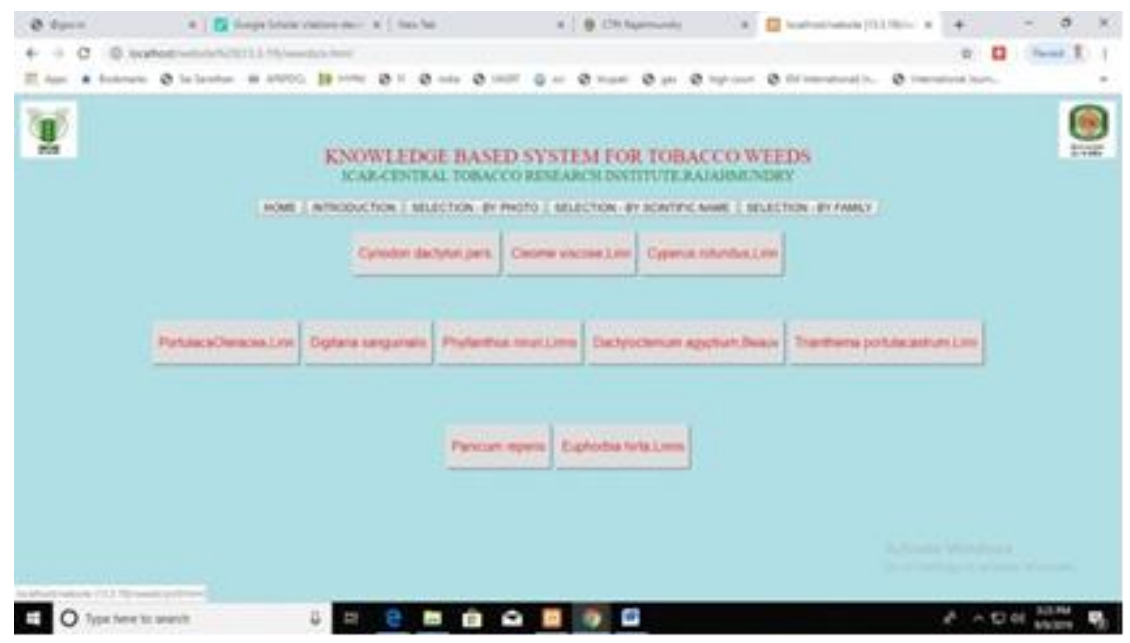

Figure.4 Selection by Scientific Name 


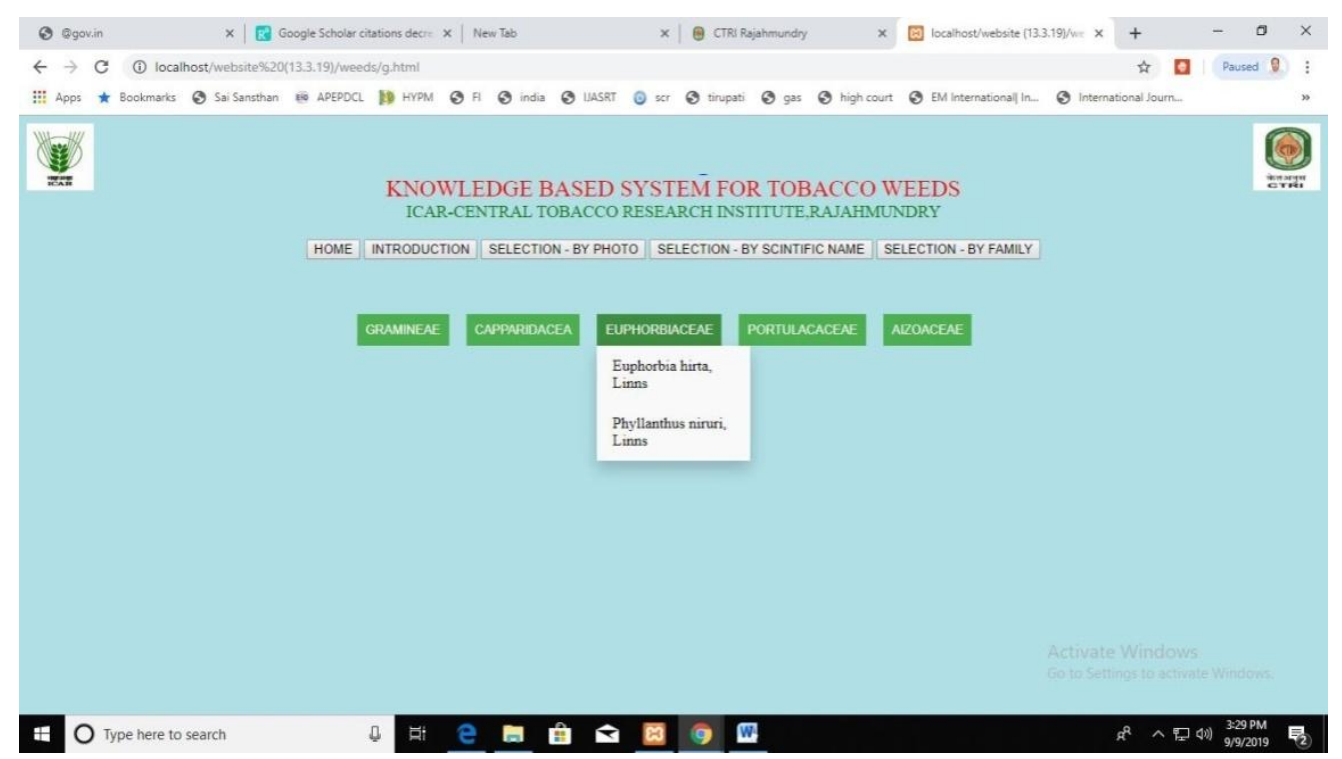

Figure.5 Selection by Family Name

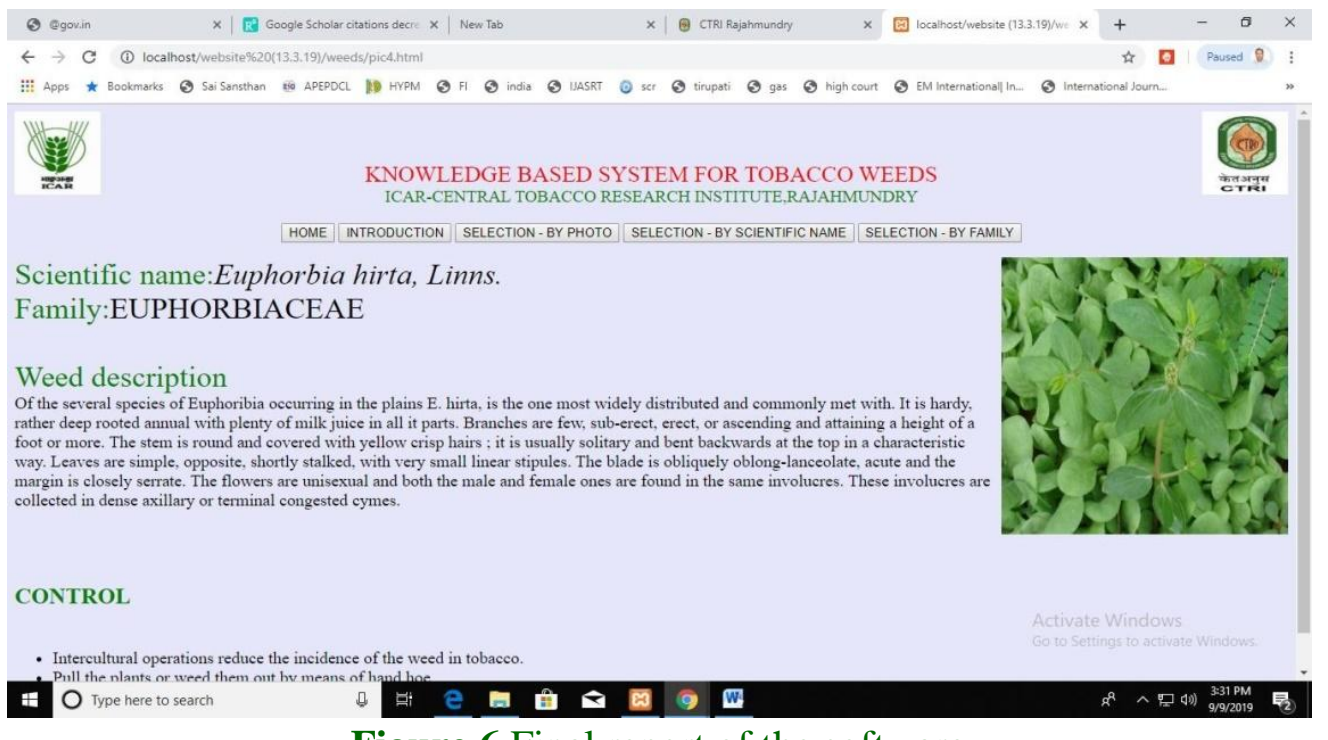

Figure.6 Final report of the software

In the second option, when the user opts for "Selection by Scientific Name" (Fig. 4) from the main menu of the software, a new screen with list of scientific names of weeds will be displayed. If the user selects one of the scientific names, a new screen with the complete information of the weed related to that scientific name is displayed.

If the user selects the third option 'Selection by Family' from the homepage, a new screen with list of the families to which all the weeds belongs gets displayed (Fig. 5). If the user moves the cursor to a particular family name, list of scientific names of all weeds under that family will be displayed. After selecting one of the scientific names of a weed from the displayed list, a new screen with Scientific Name, Family, Weed description, Control and image of the selected weed gets displayed (Fig. 6). The user is allowed to take a hard copy of the displayed report. 
In agriculture, importance of knowledgebased systems has amplified which facilitates direct transfer of technology from land to lab. With these systems, the farmer can produce higher quantity and quality of agricultural produce by using optimum resources. One third of tobacco crop yield losses are due to weeds, necessitating similar focus as that of insect pests and disease management. The developed system for tobacco weed management is useful for researchers and farmers to identify a particular weed and its characteristics with the help of Selection by Photo / Scientific Name / Family name of the weed.

This system helps to both identify the weeds causing damage to tobacco crop and provides suitable management practices in a single step. This system consists of a database of information on the different weeds in tobacco crop. This system has been installed in the local network of our institute for execution. Web based version of this software contains partial information hosted for testing. The options provided in the system are simple to execute, the tobacco weed information as per the requirements of the user can be easily retrieved, and the hard copy of the same can be obtained.

\section{References}

Ahmed Rafea. (2010). Web-Based Domain Specific Tool for Building Plant Protection Expert Systems. (Ed. Petricã Vizureanu), ISBN 978-953-307-032-2, $238 \mathrm{p}$

Andujar, G., and Luis, J. (2009). Expert System for pest, diseases and weed identification in olive crops. Expert Systems with Applications, 36(2), 32783283.

AniDath and Balakrishnan M. (2016). Expert System on Coconut Disease Management and Variety Selection.
International Journal of Advanced Research in Computer and Communication Engineering, 5(4), 242246.

Babu, M.S.P., Murty, N.V.R., and Narayana, S.V.N.L. (2010). A web based tomato crop expert information system based on artificial intelligence and machine learning algorithms. International Journal of Computer Science and Information Technologies, 1(1), 6-15.

Chakrabarti, D.K., and Chakraborty, P.A. (2007). Disease specific expert system for the Indian mango crop. Journal of Agricultural Education and Extension, 13(1), 81-82.

Donald, A.W. (2009). A guide to Expert Systems, Pearson Education Limited, USA.

Gonazalez-Andújar, J.L., Rodriguez, J., and Navarrete, L. (1990). Development of a prototype expert system (SIEXMAL) for identification of weeds in cereals, Proceedings of the European Weed Research Society, Integrated Weed Management in Cereals, Helsinki, Finland. p. 429-434.

Kiong, S.W. (2005). MobES Expert System. http://www.generation5.org/content/200 5/MobES.

Longchamp, J.P., Barralis, G., Gasquez, J., Kerguelen, P., Le Clerch, M., and Maillet, J. (1991). MALHERB, logiciel de reconnaissance des mauvaises herbes des cultures: approche botanique. Weed Research, 31,237-245

Montalvoa,M., Guerrerob,J.M., Romeob,J., Emmic, L., Guijarrob, M., and Pajaresb, G. (2013). Automatic expert system for weeds/crops identification in images from maize fields. Expert Systemswith Applications, 40(1), 75-82.

Naidu, V.S.G.R., Ravisankar, H., Sandeep Dhagat, Virendra Kamal vanshi and Sharma, A.R. (2014). Expert system for identification of weeds. International 
Journal of Applied Research on Information Technology and Computing, 5(1), 48-54.

Pasqual, G.M. (2013). Development of an expert system for the identification and control of weeds in wheat, triticale, barley and oat crops, Computers and electronics in agriculture, p. 117-134.

Patterson, D.W. (2004). Introduction to Artificial Intelligence and Expert Systems, Prentice-Hall, New Delhi.

Prasad, R., Ranjan, K.R., and Sinha, A.K. (2006). AMRAPALIKA: An expert system for the diagnosis of pests, diseases, disorders in Indian mango, Knowledge Based Systems, 19(1), 9-21.

Ravisankar, H., Sreedhar, U., and Sivaraju, K. (2014). Expert system for insect pests of agricultural crops. Indian Journal of Agricultural Sciences, 84(5), 607-11.

Ravisankar, H., Sivaraju, K., and Sumankalyani, K. (2012). Expert System for identification and management of tobacco diseases, Indian Journal of Plant protection, 40(2): 9598.

Ravisankar, H., Anuradha, M., Chandrasekhararao, C., Nageswararao, K., and Krishnamurthy, V. (2009a). Expert System for the diagnosis of nutrient deficiencies in flue-cured tobacco, Indian Journal of Agricultural Sciences, 79(1),45-49.

Ravisankar, H., Sarala, K., Krishnamurthy, V., and Rao, R.V.S. (2009b). A software system for tobacco germplasm data, Plant Genetic Resources, 7(1), $139-41$.

Ravisankar, H., Siva Raju K., Krishnamurthy, V., and Raju, C.A. (2010). Expert system for identification and management of abiotic stresses in tobacco, Indian Journal of Agricultural Sciences, 80(1),151-154.

Sarma, S.K., Singh, K.R., and Singh, A. (2010). An Expert System for diagnosis of diseases in Rice Plant, International Journal of Artificial Intelligence, 1(1), $1-6$.

Sabzia,S., Abbaspour, Y., Ginés, G., and Mateosb, G. (2018). A fast and accurate expert system for weed identification in potato crops using meta heuristic algorithms, Computers, 98,80-89.

Schulthess, U., Schroeder, K., Kamel, A., AbdElGani, A.M., Hassanein, E.E., AbdElHady, S.S., AbdElShafi, A., Ritchie, J.T., Ward, R.W., and Sticklen, J. (1996). NEPER-weed: a picturebased expert system for weed identification, Agronomy Journal, 88, 423-427.

Spangler, A.M., Ray, C.D. and Hamaker, K. (2003). Knowledge acquisition for expert system development, Computers and Electronics in Agriculture, 4(1), 2332.

Vikram Vaswani. (2017). MySQL(TM): The Complete Reference. McGraw Hill Education, 570p.

\section{How to cite this article:}

Ravisankar. H., S. Kasturi Krishna, D. Damodar Reddy, V. S. G. R. Naidu and Hema. B. 2020. Knowledge-Based System for Tobacco Weed Management. Int.J.Curr.Microbiol.App.Sci. 9(06): 1312-1319. doi: https://doi.org/10.20546/ijcmas.2020.906.163 